\section{Freeman-Sheldon (whistling face) syndrome in a Turner mosaic}

A 5 month old female child had a characteristic pinched face owing to microstomia, protruding lips as in whistling, and a receding chin with a dimple below the lower lip. Her mouth was always open. The nose was prominent and the ears low set and deformed (figure). There was congenital talipus equinovarus in both feet. There were contractures of the right third, fourth, and fifth fingers and the left second, third, fourth, and fifth fingers (figure). The chest was shield shaped with widely spaced nipples, almost in the anterior axillary line. The external genitalia were normal. There was no history of lymphadenopathy.

Received for publication 15 November 1983 Accepted for publication 13 February 1984.

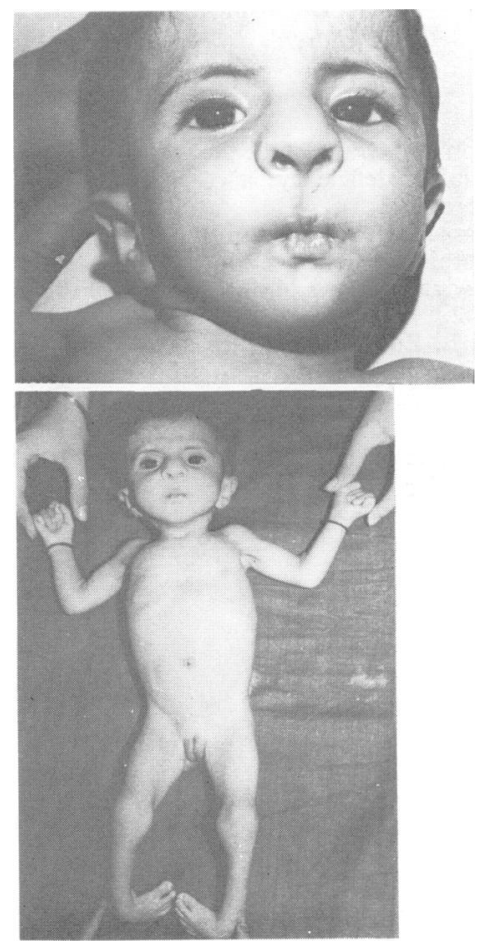

FIGURE The proband aged 5 months.
The baby was born at term after a normal delivery. She was the second child born to young, healthy, nonconsanguineous parents. The mother was 22 years of age and the father 30 years. The baby had a good cry and there was no cyanosis at birth. The mother had not taken any drugs and had had no exposure to $x$-rays during pregnancy. There was no family history of a similar case. The parents had a normal $2 \frac{1}{2}$ year old daughter.

Radiological examination showed a large part of the coccyx to be missing and the heart to be boot-shaped. Karyotyping revealed mosaicism. In 25 metaphases examined, $56 \%$ of the lymphocytes were $46, \mathrm{XX}$ and $44 \%$ were $45, \mathrm{XO}$.

This syndrome was first reported by Freeman and Sheldon in $1938^{1}$ and only 36 cases have been reported to date. ${ }^{2}$ Fraser $e t a l^{3}$ have reported cases in father and son. In the present report both parents were healthy and the baby was a Turner mosaic. Shield shaped chest and widely spaced nipples are features of the Turner phenotype and not of the Freeman-Sheldon syndrome. We conclude that they are an expression of the $\mathrm{XX} / \mathrm{XO}$ mosaicism in our patient.

The Freeman-Sheldon syndrome follows autosomal dominant inheritance. ${ }^{2}$ As the parents are unaffected we conclude that our patient represents a new dominant mutation. There is no consanguinity and nothing to suggest either autosomal recessive inheritance or genetic heterogeneity. Although the coexistence of Turner mosaicism and the Freeman-Sheldon syndrome in the same patient is of interest, we are unable to suggest an mechanism by which the two could be causatively linkeg

Meena Bajaj and Lata Mehta Genetic Division, Department of Anatomy, Grant Medical College and J J Group of Hospitals, Byculla, Bombay 400008, India.

\section{References}

1 Freeman EA, Sheldon JH. Craniocarpotarsal dystrophy. An undescribed congenital malformation. Arch Dis Child 1938;13:277-83.

2 Smith DW. Recognizable patterns of human malformation. 3rd ed. Philadelphia, London: Saunders, 1982:159-61.

3 Fraser FC, Hermine $P$, Kadish ME. Cranio-carpotarsal dysplasia. JAMA 1970;211:1374-6.

Correspondence and requests for reprints to $\operatorname{Dr} L N$ Mehta, Genetic Division, Department of Anatomy, Grant Medical College, Byculla, Bombay 400008, India 